\title{
Práticas de leitura e formação docente: reflexões a partir de fragmentos de um percurso
}

\author{
Carlos Toscano*
}

\begin{abstract}
Resumo
O presente artigo propõe delinear como se configurou, num percurso singular, o encontro com os textos e o contexto no qual, mediado pela leitura, certas práticas culturais, a partir da escola, e se entrelaçaram na constituição de um leitor e professor. Apoiado no referencial teórico proposto por Bakhtin e Vigotski, recorro a fragmentos de meu percurso de formação, compondo com eles uma narrativa na qual destacam-se os outros que comigo interagiram e as marcas que essas interações e a leitura produziram em mim. Como resultados destacamse: o tipo de leitor resulta de um processo histórico, social e cultural que se singulariza no percurso de formação de um sujeito por meio de um conjunto de aprendizados. A compreensão do professor-leitor que somos, historicamente, requer que se leve em consideração que práticas culturais se tornaram acessíveis e como foram vividas pelos sujeitos nas relações sociais.
\end{abstract}

Palavras-chave: Educação; Escola; Formação de professores; Formação de leitores.

\section{Practices of reading and teacher formation: Reflections from fragments of a route}

\begin{abstract}
This paper aims to outline how, in a singular way, an encounter took place with the texts and the context in which, mediated by reading, certain cultural practices intertwined to form a reader and a teacher. Supported by the theoretical framework proposed by Bakhtin and Vigotski, I use fragments of my formation journey tying them up with a narrative in which stands out those that interacted with me and the marks that these interactions and reading left in me. The results include: the reader is result of a historical process, social and cultural that singularizes in the course of formation of a subject through a set of learnings. It is intended to describe the formation path of a reader-teacher, as a set of learning experiences and, in this perspective, the need to take into consideration that cultural practices have been made available and how they were experienced by the subjects, in social relations. Keywords: Education; School; Teacher formation; Reader formation.
\end{abstract}

\section{Introdução}

A condição de leitor de professores/as tem sido objeto de atenção nos últimos anos. Alguns estudos, como os realizados por Gatti et al. (1994) e Setton (1994), acabaram por enfatizar uma representação do professor como não-leitor. Em outros estudos, Batista (1998), Britto (1998), Guedes-Pinto (2002), Lahire (2004), dentre outros, por caminhos diversos, problematizaram esta representação do professor como não leitor e, ao assumirem outra perspectiva, acabaram destacando a diversidade de modos de ler e possibilitando uma visualização dos variados percursos de constituição de leitores-professores.

Os estudos realizados por Guedes-Pinto (2002) e Orlandi $(1993,1996)$ se entrelaçaram aos achados da pesquisa realizada por ocasião do doutorado e acabaram provocando em mim o incentivo necessário para realizar uma reflexão em torno de como aprendi e fui me tornando leitor e produtor de textos. Para tanto, busco compartilhar, neste texto, alguns fragmentos de meu percurso de formação, focalizando alguns acontecimentos que mediaram meu encontro com textos.

Considerando que não nascemos, mas nos tornamos leitores nas tramas do processo de constituição de nossa experiência e subjetividade, a narrativa, ancorada na rememoração, apresentou-se como uma forma privilegiada para tornar visível a mediação daqueles que participaram das relações sociais nas quais emergiram diferentes possibilidades de significado e de significação na relação com a palavra escrita.

As narrativas por mim reunidas remetem a diferentes espaços e tempos, a situações ou contextos sociais mais imediatos e também a contextos mais amplos que acabaram por determinar as condições de produção desse imediato. Antes, porém, pretendo apontar para o conjunto de pressupostos que nortearam sua elaboração.

\section{Das ideias que nortearam este estudo no âmbito teórico e metodológico}

* Endereço eletrônico: ctoscano@uel.br 
Este estudo, resultante de uma pesquisa mais ampla como tese de doutorado, assume que a gênese do especificamente humano e a constituição das singularidades dos sujeitos situam-se nas práticas sociais, destacando, nesse processo, o papel do outro e da mediação semiótica.

Neste trabalho, tendo em vista as repercussões que em mim se produziram os estudos de Bakhtin, acabei tomando-o como referência maior e, por isso, destaco as questões tratadas por ele que, por assim dizer, mediou esta elaboração.

Para este autor, a partir do momento em que nascemos, somos introduzidos em um mundo préexistente: o mundo humano. Isso coloca, desde logo, uma necessidade de aprender esse mundo em funcionamento, processo esse que passa necessariamente pelo outro de nossas relações, mediado por signos, produzidos no percurso histórico pelos diferentes grupos de indivíduos socialmente organizados nas interações sociais.

Bakhtin (2001, p. 11) fala, inclusive, de um segundo nascimento, o nascimento social, que se segue ao nascimento biológico. Explica que:

Para entrar na história é pouco nascer fisicamente: assim nasce o animal, mas ele não entra na história. [...] O homem não nasce como organismo biológico abstrato, mas como fazendeiro ou camponês, burguês ou proletário: isto é o principal. Ele nasce como russo ou francês e, por último, nasce em 1800 ou 1900. Só essa localização social e histórica do homem o torna real e lhe determina o conteúdo da criação da vida e da cultura. (grifos do autor).

Esta localização do homem singular no tempo e no espaço de sua existência permite situá-lo no processo histórico e social, de modo que se possa compreendê-lo nas relações sociais pelas quais vai se apropriando da realidade, ao mesmo tempo em que vai interferindo nela e edificando sua biografia. Biografia marcada pelos lugares sociais ocupados, pelas interlocuções produzidas no diálogo ininterrupto da cadeia de comunicação verbal.

De acordo com Bakhtin (2000, p. 313),

A época, o meio social, o micromundo - o da família, dos amigos e conhecidos, dos colegas - que vê o homem crescer e viver, sempre possui seus enunciados que servem de norma, dão o tom; são obras científicas, literárias, ideológicas, nas quais as pessoas se apoiam e às quais se referem, que são citadas, imitadas, servem de inspiração. Toda época, em cada uma das esferas da vida e da realidade, tem tradições acatadas que se expressam e se preservam sob o invólucro das palavras, das obras, dos enunciados, das locuções, etc.

Nesse processo, a linguagem e os outros com quem interagimos assumem um papel fundante, efetivamente constitutivo. E, concebido dessa forma, nosso processo de constituição como sujeitos humanos é perpassado pelas aprendizagens que vamos realizando ao longo da vida desde o instante do nascimento. Isso, por sua vez, significa adentrar um território já habitado por vários outros, o que vale dizer, apreender essa parte do mundo humano que se coloca disponível ao indivíduo de forma social e semioticamente mediada.

Sob essa perspectiva, o processo de constituição de um sujeito, ou de uma consciência individual, realiza-se na interação como os outros, resultando na coabitação de muitas "palavras" ou "vozes", que, de acordo com este autor, são sociais e lutam por sua influência, da mesma forma que lutam na realidade social.

$\mathrm{Na}$ compreensão do processo formativo do sujeito, que ele expressa como formação ideológica do homem, esse autor chama a atenção para a importância das palavras alheias nos processos de interação. Para ele, a assimilação das palavras de outrem adquire um sentido mais profundo e mais importante visto que ela [a palavra de outrem] "[...] procura definir as próprias bases de nossa atitude ideológica em relação ao mundo e de nosso comportamento, ela surge aqui como palavra autoritária e como palavra interiormente persuasiva" (BAKHTIN, 2002, p. 142).

De acordo com Bakhtin (2002, p. 143), enquanto a palavra autoritária exige de nós "o reconhecimento", "permanecendo nitidamente isolada, compacta e inerte", a palavra persuasiva permite "elaboração" e "enquadramento" bastante flexíveis.

Ao caracterizá-las desse modo, ele chama a atenção para o fato de que ambas participam do processo de formação ideológica. No entanto, destaca que a palavra persuasiva é determinante para o processo da transformação ideológica da consciência individual, uma vez que ela, no processo de sua assimilação positiva, entrelaça-se 
estreitamente com a nossa "palavra", desenvolvendo-se e adaptando-se ao novo material, às novas circunstâncias, aos novos contextos.

Bakhtin (2000, p. 314) destaca ainda que, por intermédio da palavra do outro, o indivíduo elabora o mundo e é elaborado por ele num processo de "assimilação, mais ou menos criativo da palavra do outro". Afirma ainda que, nesse processo, "a palavra do outro se transforma, dialogicamente, para tornarse 'palavra pessoal-alheia' com a ajuda de outras palavras do outro, e depois, palavra pessoal', quando tem um caráter criativo e torna-se anônima, ou familiar, numa forma reestruturada (BAKHTIN, op. cit., p. 406).

Nessa etapa, a consciência se monologiza, "esquecendo-se" da relação dialógica original com a palavra do outro, para, em seguida, inserir-se num novo diálogo como novas vozes do outro.

$\mathrm{Na}$ perspectiva desse autor, a consciência humana, repleta de signos e constituída na relação com os outros, é habitada por múltiplas vozes sociais, revelando, assim, uma concepção fundamentalmente social e semiótica do sujeito. Ao mesmo tempo, considera-se a constituição de um sujeito singular como uma articulação "única" dessas vozes, elaborada na interação viva com elas. Nesse sentido, o outro, seja presente, seja distante, situado inclusive em outra temporalidade, que dialoga conosco indiretamente, fala em nós da mesma maneira que nós falamos nos e pelos outros (FONTANA, 2006, p. 229).

Encontramos nesse autor uma concepção de sujeito que se constitui nas relações sociais, nos diferentes lugares sociais que se vai ocupando ao longo de sua existência. Isso significa que esse sujeito é social, na medida em que a origem do alimento e a lógica de sua consciência são externos a ele inicialmente. E também singular, visto que articula e responde de modo único às condições e contradições que se lhe apresentam ao longo da vida.

Mediado pelas contribuições teóricas de Bakhtin, narro e depois analiso três fragmentos de meu percurso de formação, privilegiando o encontro com textos e as práticas de leitura relacionadas a eles e que, por assim dizer, direcionaram meu percurso de formação de um leitor. Para falar de tais encontros, entretanto, tornou-se necessário destacar os outros que, nesse processo, foram os mediadores e fornecer pistas dos contextos onde eles se deram e os lugares sociais ocupados por eles e por mim nas interações sociais nas quais ocorreram os acontecimentos.

A narrativa, aqui apresentada em forma de fragmentos, resulta de uma produção na qual eu sou instigado por um outro e, em face desse outro que me indaga e me instiga, eu rememoro e narro e, ao fazêlo, acabo rememorando também para mim. Essa marca coloca uma primeira diferença em relação à autobiografia, uma vez que eu me dobro sobre o rememorar num exercício que envolve certa reflexividade, que surge provocado por um outro e alimentado também por ele. Esse outro me leva a uma rememoração que não se centra numa busca de mim mesmo, com o desejo de conhecer a mim mesmo, mas num trabalho de rememoração que me leva ao encontro do meu percurso de formação. Assim, eu me volto para o passado com o intuito de responder às indagações do outro sobre o meu percurso e não sobre eu mesmo ou a respeito de mim.

Ocorre que esse percurso só é possível de ser recuperado nas relações. Então se coloca que o foco para a solicitação desse outro para que eu rememore se localiza nas relações vividas. Configura-se assim uma segunda diferença em relação à autobiografia que, de acordo com Bakhtin (2000), tem como princípio constitutivo ser uma auto-objetivação na qual apenas a relação pura do eu consigo mesmo pode ser o organizador do discurso na qual o outro, com sua abordagem específica, privilegiada, fica excluído.

Neste trabalho, no qual fui ao encontro de meu percurso formativo a partir de uma indagação apontada por um outro, eu pude apreendê-lo somente nas relações com o outro e, sendo assim, o foco não sou eu mesmo, mas as relações que eu vivi. E sobre elas eu só posso falar nas tensões com o outro. Daí que o destaque na narrativa recai sobre os meus personagens que são os meus outros com quem interagi neste percurso formativo: o pai, a mãe, o amigo, o pai do amigo, a professora de História, o professor de Biologia, e que, portanto, entraram em tensão comigo.

No interior destas tensões que configuram o processo constitutivo, se encontram os dramas, da qual nos fala Vigotski (2000, p. 35), como dinâmica da personalidade, repleto de luta interna; portanto a nossa singularidade em ato e também as tramas, que dizem respeito às dinâmicas relacionais nas quais se produz a singularidade. As tramas do processo constitutivo, neste caso, dizem respeito aos diferentes espaços e tempos e, portanto, envolvem situações ou contextos sociais mais imediatos, onde se deram os acontecimentos, e também os contextos sociais mais amplos que os envolvem e as quais eles se ligam. 


\section{Fragmentos de um percurso}

1. Possibilidades no âmbito da família

Para meus pais, como resultado das várias determinações sociais, a escola fora um momento e uma experiência bastante episódica em suas trajetórias, embora representasse para eles uma forma privilegiada de acesso a um mundo outro, em que se poderiam ocupar lugares sociais distintos daqueles que lhes foram permitidos.

No espaço familiar, a circulação do material escrito ficava mais a cargo de minha mãe, com as revistas compradas em banca de jornal, que, à época, eram dirigidas ao público feminino, e outras publicações, como almanaques e materiais de divulgação, que eram distribuídos em alguns espaços públicos, como farmácias e lojas. Outros materiais que chegavam até mim eram os gibis, lidos para mim por minha mãe, e álbuns de figurinhas com motivações variadas, como times de futebol e artistas de rádio e TV. Nesse contexto, os momentos de leitura e a figura de leitora ficavam associados à minha mãe, embora meu pai tivesse também momentos de leitura voltados para o jornal de esportes da época. Nos demais materiais escritos a que ele tinha acesso, somente alguns poucos ele tomava à mão para fazer uma leitura muito singular, fixando-se quase que exclusivamente nos títulos, com suas letras em maior tamanho e, por vezes, uma tentativa de iniciar a leitura do primeiro parágrafo, que, na maioria das vezes, não chegava a concluir.

A produção da escrita da contabilidade das despesas da casa ficava mais centralizada em meu pai, quando da conferência dos lançamentos dos itens comprados, no dia a dia, na venda e no açougue, com seus respectivos valores, bem como na realização ou conferência da totalização das importâncias a pagar em cada mês. Minha mãe também tinha seus momentos com a escrita, ao escrever cartas para uma amiga e vizinha que tinha se mudado para outro estado, além de recados e receitas culinárias. Particularmente com relação à leitura dessas cartas, minha mãe assumia o lugar de leitora da família e, assim sendo, fazia a leitura em voz alta para mim e meu pai. O mesmo procedimento era realizado após a escritura da reposta.

Uma expectativa quanto à escolarização, em decorrência do conhecimento propiciado pelas letras, como de outras possibilidades profissionais se manteve para ambos. E, por isso, pai e mãe desejaram, possibilitaram e sustentaram minha condição de estudante, que teve início nos primeiros anos da década de 1960.

2. Na escola, o acesso a textos e a produção de necessidades que me levaram a outros interlocutores:

Fui me inserindo na cultura escolar sem encontrar maiores dificuldades, contando com o incentivo dos meus pais e com a ajuda de minha mãe nos primeiros anos desse processo. A partir de então, sempre que solicitados, os materiais escolares eram objetos de leituras compartilhadas entre nós, mas, à medida que a escolaridade avançava, suas possibilidades de contribuições ficavam mais restritas.

Na chegada ao colégio (atual ensino médio), em 1970, situado no bairro da Pompéia da cidade de S. Paulo, a situação se alterou bastante, quando tive uma aproximação diferenciada com a História do Brasil, no que se refere ao tipo de texto que foi oferecido pela professora e no modo muito particular de lidar como ele.

O livro indicado, Formação Econômica do Brasil, (Furtado, 1970), provocou um profundo impacto pela dificuldade de compreensão, pelo vocabulário utilizado, além das citações em língua inglesa. Ao mesmo tempo, foi saboroso pelo jeito como a professora lidava com a disciplina, misturando empolgação, engajamento $e$ exigência. $O$ texto transformava-se no momento em que a professora lia para nós certos trechos em voz alta, numa fisionomia expressiva de quem o interpretava. Ao fazêlo, o texto já era outro, marcado por sua entonação, destaques, comentários. Na aula, ela, de sua cadeira e próxima à mesa, tinha à sua disposição outros materiais que eram compartilhados conosco: outros trechos 
lidos, figuras ou ilustrações comentadas, dentre outros. E isso me incitava a ir ao seu encontro para o estudo posterior, tentando a leitura, buscando dicionários para os termos novos que surgiam e ajuda com leitores mais experientes e outros livros que abordassem o mesmo assunto. Um mundo de novas palavras se apresentava a mim: feudalismo, servos, vassalos, empresa agrícola, não obstante, capitalismo, processos históricos, etc., com as quais eu passava a ter uma relação de estranhamento, uma vez que elas não se ligavam aos conhecimentos adquiridos, mas que, ao serem veiculadas pela professora com tamanha intimidade, numa expressão iluminada, repercutiam em mim como um chamamento, incitando-me a ir ao encontro das chaves que possibilitassem minha entrada naquele território tão desconhecido e ao mesmo tempo tão instigante.

Na disciplina Biologia, cujo professor, como a de História, também trabalhava na Universidade de São Paulo, foi possibilitado o conhecimento da teoria da evolução (BRASIL/UNESCO/BSCS, 1969). Esse tema, da forma como o professor lidou, mexeu com toda a classe, dando margem a abordagens que iam da filosofia à religião, passando pela questão do conhecimento e da ciência. E com o texto, entremeado de questões, éramos incitados a refletir sobre um mundo novo e era também um desafio. Para alguns colegas, o texto proposto foi rapidamente percebido como divergente das proposições de origem religiosa e, assim, dentre estes, alguns se "rebelavam", sustentados por suas convicções. Já outros incitavam o professor a que aprofundasse o esclarecimento das diferentes premissas entre as diferentes teorias. Outra parte da turma, na qual me incluía, acompanhava os acontecimentos. No meu caso, não me sentia confrontado, mas um pouco admirado pela novidade do tema, que me apresentava um mundo que eu não supunha existir, e pelo vivo debate que suscitava, por ser tão incomum nas aulas que havia frequentado até aquele momento.

A falta de compreensão das novas palavras apresentadas, tanto para mim como para outros colegas acabou gerando a necessidade da formação de um grupo de estudos. Assim, eu e mais três colegas de classe passamos a nos encontrar na casa dos meus pais, diariamente, após as aulas, para dar conta das atividades que nos eram propostas. Para as disciplinas acima referidas, passamos a fazer uma leitura coletiva, em voz alta, com muitas idas $e$ vindas, avanços e recuos, tentativas de explicação do que estava sendo compreendido.

Além disso, o compartilhamento de referências obtidas em outros espaços também era objeto de leitura nos trechos que tinham relação com o assunto estudado. Nesse sentido, apontava-se, nesses encontros, certa metodologia de estudo para o enfrentamento dos textos que nos eram oferecidos, assim com uma grande diferença entre nós no repertório de conhecimentos adquiridos até aquele momento e que podiam constituir pontos de partida para a compreensão daquilo que era objeto de estudo.

$O$ ponto chave do processo era o compartilhamento dos significados que se produziam com a leitura que realizávamos coletivamente, e um dos participantes do grupo de estudos se sobressaía. Ele trouxera boas contribuições de uma escola situada no interior do estado de São Paulo, que, aparentemente, estaria mais organizada e propiciava um ensino mais consequente; além disso contava ele com uma vivência familiar em um meio cultural muito mais próximo daquilo que estava sendo solicitado a nós naquele momento, por intermédio daquelas disciplinas escolares.

A cogitação de nos tornar professores, que ocorreu somente a mim, nasceu desses encontros, que eram vividos por mim como apresentação sedutora dos conhecimentos aos quais eu não tinha tido acesso e no prazer do seu compartilhamento, percebido na ação daqueles professores e do amigo.

$\mathrm{Na}$ passagem para o segundo ano, que coincidiu com a mudança para o período noturno, uma grande alteração no curso colegial foi introduzida com a profissionalização obrigatória, estabelecida pela nova lei de diretrizes da educação nacional, Lei 5692, e acabei por constituir,

Horizontes, v. 34, n. 1, p. 123-136, jan./jul. 2016 
com uma colega da nova turma, outro grupo de estudos, que se mobilizou para a encenação de uma peça realizada como trabalho da disciplina de Psicologia e, também, para um trabalho em grupo sobre o tema "Brasil Atual" na disciplina de Organização Social e Política do Brasil.

A preparação do texto $e$ da encenação da peça, assim como a elaboração do trabalho com a reconstituição do grupo de estudos, levoume a uma aproximação com a família de um amigo, trazendo outros desdobramentos. $\mathrm{Na}$ medida em que passei a frequentar a casa do amigo, pude interagir de maneira mais sistemática com ele, com seu irmão e com seus pais.

3. O amigo e a sua família

$\mathrm{Eu}$ o conheci no colegial quando a professora de Português nos passou uma tarefa para casa nos primeiros dias de aula. Ele, um sujeito magro, de óculos e com um sotaque que o distinguia de nós, por acaso, como se dá quando se entra na sala de aula no primeiro dia do ano letivo, encontrava-se próximo a mim, sentado na cadeira que se localizava à direita da minha e confidenciou que uma tia professora tinha o material de que precisávamos e que nós poderíamos ir a casa dela fazer a tarefa.

Ele era recém-chegado de uma cidade do interior de São Paulo e, havia poucos dias, estava agora morando na capital. A ida à casa de sua tia para fazer a pesquisa necessária ao trabalho deu início a uma amizade que incluiu toda a sua família $e$ continua até hoje.

O pai de meu amigo, naqueles tempos de perseguição política extremada, aposentara-se, "compulsoriamente", do serviço público estadual e buscava sobreviver na nova cidade com alguma atividade profissional que lhe era ofertada por outras pessoas de suas relações.

A mãe dele, professora primária, também antecipara sua aposentadoria para não ver subtraídos seus direitos trabalhistas diante da ameaça de alteração da lei que regulava $o$ tempo de serviço profissional, $e$, rememorando o tempo em que atuava em escolas rurais, se orgulhava de ter alfabetizado a garotada do campo. Seu trabalho empenhado trouxe reconhecimento na sociedade local, na qual não era incomum a manifestação do desejo de tê-la como professora dos/as filhos/as, de modo que acabou inspirando a filha a seguir a mesma profissão. Com os acontecimentos, resolveu trabalhar nos serviços da casa após a aposentadoria, ainda que mantivesse a leitura no rol de suas atividades prediletas. $O$ irmão de meu amigo, de cabelos longos e óculos redondos, era estudante $d a$ universidade, conforme já apontado, e sua irmã havia se casado recentemente, exercia a profissão de professora primária e morava também na cidade de São Paulo.

Desse acontecimento quase fortuito foram se desdobrando muitos outros que redirecionaram o curso da existência. De colega de classe, passamos a amigos que saíam nos finais de semana e, assim, fui progressivamente adentrando em sua casa, inicialmente para pernoitar nos finais de semana. Com o tempo, além do pernoite, ficava para o almoço de domingo, o papo da tarde, o café no início da noite, etc.

Quando da primeira vez que eu estive em sua casa, chamou-me a atenção a quantidade de livros e revistas que eles tinham.

A casa, pela característica do terreno em que fora construída, tinha um piso térreo, situado no mesmo nível da rua onde ficavam a sala, uma pequena cozinha e uma varanda que delimitava o terreno e a construção, mas que possibilitava uma bela vista dos arredores do bairro; em um andar acima deste, ficavam dois quartos, um voltado para a frente e outro para o fundo do terreno, além de um banheiro, o que tornava a construção um típico sobrado quando se olhava da rua. Mas tinha ainda um andar abaixo em relação à rua. Neste último, havia uma biblioteca onde se concentravam romances, enciclopédias, dicionários, revistas, livros abordando os mais variados temas: educação, filosofia, política, história do Brasil e do mundo, etc. Ali, também se encontrava um dormitório e um banheiro.

Eles tiveram uma livraria na cidade onde moraram antes de se mudarem para a capital de São Paulo e, além disso, gostavam 
muito de ler.

$\mathrm{Na}$ medida em que minha assiduidade naquela casa aumentava, pude vivenciar com eles um hábito que me pareceu incomum e surpreendente que me cativou: uma forma de conviver com os livros, buscálos durante uma conversa, ler pequenos trechos para si e para os outros; comentar o lido, viajar no pensamento do autor $e$ construir o próprio pensamento.

Ocorriam, de forma rotineira, discussões de temas variados: desde matérias jornalísticas localizadas na política, na economia, nas cidades. Programas de televisão eram debatidos em "tempo real"; leituras comentadas de poesias eram realizadas; trechos de romances eram lidos ou relembrados, enriquecendo as conversas ou se tornavam objetos de discussão.

Tudo isso tornava visível como se dava a incorporação e a forma de lidar com um grande conjunto de informações às quais eles tinham acesso. Seja através das visitas de pessoas de suas amplas relações que traziam informações de várias partes e em distintos campos, mediados pela fala e, particularmente, pela palavra escrita.

Enquanto, via de regra, a leitura e o contato que eu tivera com os livros se restringiam ao "obrigatório", ou à "falta" de alternativas mais interessantes, lá eu verificava um imenso sabor no trato com os diferentes tipos de texto.

Esse imenso acervo, que não cessava em dinamizar-se no processo dialógico e em ser atualizado, na realidade, constituía-se numa forma possível, nas condições existentes naquele momento, de ser contemporâneo do mundo, entrar em contato com as produções humanas em suas várias naturezas e campos e com as diversas partes do mundo. Era parte de uma necessidade vital dos integrantes daquela família dialogar com os demais não apenas face a face, no tempo e no espaço, mas como uma forma de orientar o pensar e o agir. A isto juntava-se uma disposição imensa para uma transformação no cotidiano, na relação entre as pessoas no dia a dia: seja no comércio, no trabalho, na vizinhança.

Minha continuada presença e minha progressiva identificação com os valores que ali se veiculavam fizeram com que eu passasse a fazer parte integrante daquela família, tal foi o modo com que nossos laços se estreitaram e se aprofundaram. Nesse processo de intensa e progressiva pertença àquela família, fui entrando em contato com vários interlocutores que nesse momento tornavam-se, por assim dizer, documentos de formaçãol.

Alguns lugares também foram importantes, porque representavam espaços que envolviam ampliação das referências $e$, de certo modo, punham-me em contato com outras produções humanas. Vale a pena destacar: o Museu de Arte de São Paulo (MASP), o Museu de Arte Moderna (MAM), o Museu Lasar Segal, o Teatro do SESI, além do Centro Cultural do Equipe, as salas de cinema de Arte e Cineclubes, livrarias, dentre outros. Suas programações diferenciadas indicavam outras possibilidades de tomada de conhecimento de variadas produções culturais nacionais e internacionais. Assim, Rosellini, Nelson Pereira dos Santos, Bunuel, Glauber Rocha, Fellini, Zefirelli, Pasolini, dentre outros, começaram a fazer parte do "meu circuito". Além disso, podem-se destacar outras publicações que subsidiaram e mediaram as interlocuções, começando pelo jornal diário e chegando até os periódicos, como as revistas O Correio da UNESCO, Visão, Revista Civilização Brasileira. Aos poucos, por fazerem parte de minhas leituras $e$ estudos, elas acabaram introduzindo novas questões, preocupações e proposições de âmbito nacional e internacional.

O pai de meu amigo era também um grande contador de histórias. Narrava episódios de sua vivência, histórias contadas por outras pessoas de suas relações e que, com o tempo, passaram a fazer parte de suas histórias. Esses momentos compuseram a forma mais comum de acolhimento, não apenas porque me informavam sobre eles, mas, sobretudo, porque tais situações implicavam formas de aconselhamento e de orientação.

Duas imagens foram se consolidando: a do amigo, companheiro de convivência no dia a dia na escola, nas programações culturais e nos estudos e a dos pais de meu amigo, que, juntamente com seu irmão, acolheram-me de

Horizontes, v. 34, n. 1, p. 123-136, jan./jul. 2016 
forma ampla e irrestrita, inserindo-me na dinâmica de suas existências.

\section{Análise dos fragmentos}

É possível encontrar na narrativa acima, na qual se registrou o resultado obtido com o processo de rememoração, episódios que envolveram a família, a escola, a família de meu amigo, e outros personagens a eles associados, como também textos, lugares e ações que se desenvolveram em cada um desses espaços.

A rememoração, sempre provocada por outro, o seu registro, sua posterior seleção e reorganização, com o suporte das ideias norteadoras anteriormente apresentadas, acabaram por evidenciar, tendo em vista o contexto específico que orientou todo esse processo, diferentes tipos e modos de ensino, de aprendizagem e de formas de interação. Em consequência, os diferentes lugares sociais ocupados e suas variadas condições de produção acabaram por circunscrever um percurso de formação, no qual se insere a formação de certo tipo de leitor, que se converte em diferentes tipos e formas de aprendizados.

Assim, a formação de um leitor passa a ser entendida como o conjunto de aprendizados que vão se entrelaçando, se desenvolvendo, sendo recortados e reconfigurados à medida que se alteram os contextos, as pessoas e as formas de interação, considerando-se que a inserção do humano num determinado ambiente cultural, conforme já salientado anteriormente, circunscreve sua própria condição de constituição.

A consciência, esclarecem Bakhtin e Volochinov (2002, p. 35-36), adquire forma e existência nos signos criados por um grupo social organizado no curso de suas relações sociais. Os mesmos autores afirmam ainda que a realidade dos signos constitui também a realidade dos fenômenos ideológicos, sempre atravessados por índices de valor.

Ainda que os processos interativos tenham especificidades, uma vez que o lugar social ocupado por mim se diferenciou - filho, amigo, amigo do filho, amigo do irmão, em todos eles - o aprender se destaca como central e comum a todos eles, e o mesmo se dá quando na condição de aluno.

No decorrer desse processo marcado pela ação do aprender, vão sendo progressivamente incorporados novos elementos e se ampliam as temáticas, os materiais, os lugares e as atividades.
Entraram em cena certas polêmicas, debatidas em jornais, revistas, ou em pequenos livros, que tratavam de temas da atualidade; livros de literatura, filmes, músicas, biografias, seleção de imagens, materiais de atividade prática de uso cotidiano, trechos de obras originais de cientistas, textos de peças de teatro, etc.

A ampliação das referências tornou possível um acesso e um início de um conhecimento na qual se apresentavam diferentes vozes postas em circulação, cuja origem se localizava no acesso a certas práticas culturais ligadas aos acontecimentos das décadas de 1950-1960 e que era objeto de tentativa de transmissão às gerações seguintes. Uma época de intensa movimentação na sociedade brasileira, na qual alguns temas ganharam destaque: reformas estruturais ou de base, política externa independente, combate ao imperialismo e ao latifúndio, projeto nacional de país. Alguns dos professores/as que interagiram comigo, de alguma forma, ecoavam em suas aulas esses temas por intermédio das disciplinas que ministravam e, assim, apontavam para outra forma de lidar com o ensinar e o aprender.

$\mathrm{Na}$ década seguinte, 1970, com a institucionalização das restrições impostas decorrentes da reorientação protagonizada pelos militares nos âmbitos políticos, econômicos e culturais, as condições se alteraram bastante. Conforme observam Hollanda e Gonçalves (1982, p. 97):

A crescente articulação institucional da cultura, pela via da empresa ou das agências estatais e o controle político imposto pela censura estimulam a busca de alternativas, seja no nível da produção - ali onde seria mais acessível à iniciativa "marginal", como no caso da imprensa, da literatura, de certo teatro -, seja em relação à linguagem. Aqui, toda uma retórica de alusões através de truques e metáforas é desenvolvida, notadamente na música popular. Fala-se enviesado o que não pode ser dito diretamente. Como notou Gilberto Vasconcelos, a cultura passa a ficar de "olho na fresta", procurando as brechas, o espaço descuidado que permite a malandragem da crítica metaforizada. [...] $O$ do Pasquim e mais tarde dos semanários Movimento e Opinião abre efetivamente um espaço, ainda que um tato censurado. 


\section{(Grifos dos autores).}

Os ecos que passavam pelas frestas, tornavam a escola um lugar plural no qual se entrecruzavam diferentes formas de atuação.

O sentido e o significado da leitura em cada um dos três espaços e tempos destacados nesta narrativa não são os mesmos, ao se levar em conta as especificidades de cada um dos contextos: de minha família, do amigo e sua família e da escola. O ponto em comum entre os três diz respeito ao significado que o escrito representava nestes espaços, mas em função da condição específica de cada um dos sujeitos e do lugar que ocupavam, a relação com o escrito era bastante diferenciada. A consequência dessa distinção resultou em ampliação de possibilidades, de materiais e de práticas.

A escola, que fora praticamente negada aos meus pais, como resultado das várias determinações sociais, representava uma forma privilegiada de acesso a um mundo outro, nas quais se poderiam ocupar lugares sociais distintos daqueles que lhes foram permitidos. Neles, as letras precisavam ocupar um papel secundário na forma de realização de suas atividades. Desse modo, o lugar social ocupado implicou também possibilidades de se delinear projetos nas quais apresentaram-se interlocutores e se desenharam possíveis.

$\mathrm{O}$ universo de conhecimentos e referências de meus pais no campo escolar era bastante restrito, uma vez que o trabalho precoce afastara ambos desse espaço já há bastante tempo. Consequentemente, a leitura e a escrita, as práticas e os materiais que sustentaram suas ocorrências ficaram delimitados a certos momentos e formas.

Ainda em relação ao ensino médio, antigo colegial, cabe considerar que, embora tenha sido realizado na mesma escola, ficou marcado por dois momentos muito distintos.

O primeiro ano, realizado no período matutino, continha ainda marcas de um tempo anterior, no qual a rede pública escolar viveu experiências inovadoras que tiveram certo amparo e acolhimento dos órgãos responsáveis pelo setor educacional.

De acordo com Ghiraldelli Jr. (1990, p. 128), esse momento, que se insere no esforço para a composição de um ideário em que a escola precisava acompanhar as transformações pelas quais a sociedade brasileira passava, encontramos: renovadores educacionais, liberais, socialistas, militantes das esquerdas cristãs, dentre outros. Na cidade de São Paulo, de acordo com este autor, destacavam-se várias experiências, como a dos ginásios vocacionais, o Colégio de Aplicação da USP e as escolas experimentais. No interior desses movimentos, localizava-se uma perspectiva escolar que apontava para a possibilidade de uma emancipação política pela via do conhecimento "crítico da sociedade". De certa forma, ecos dos momentos vividos pelo país até a metade da década de 1960 ainda se faziam ouvir naquele que foi o primeiro ano do colegial, através da professora de História e do professor de Biologia.

Um segundo momento muito distinto se apresentou quando da passagem para o período noturno, após a finalização do primeiro ano do ensino médio, e revelou dois aspectos da realidade escolar de então. Ficava, por um lado, exposta uma grande diferença entre o ensino realizado entre este período e o do matutino, ainda que na mesma instituição. Ela ficava marcada pelos/as professores/as, pelas atividades que nos eram propostas, pelas formas de interação que acabavam por se estabelecer, tudo isso entrelaçado aos conteúdos de ensino-aprendizagem. Nesse contexto, o universo cultural de conhecimentos se apresentava menos envolvente, mais empobrecido e mais burocratizado em rotinas desgastantes. Por outro lado, na passagem para o segundo ano, foi iniciada a implantação da profissionalização obrigatória, prevista pela nova política de educação para o setor, amparada pela Lei 5692, aprovada pelos novos ocupantes do governo federal com o golpe militar de 1964. Tal reforma foi pensada como uma forma de reduzir a pressão ante a demanda pelo ensino superior, em que se procurava uma habilitação profissional (CUNHA, 1977). Na prática, a profissionalização obrigatória acabou não se efetivando da forma como foi prevista na Lei que a instituiu, mas, ainda sim, contribuiu decisivamente para desorganizar ainda mais esta etapa da escolaridade.

Um balanço dos acontecimentos desse período, realizado por Cunha e Góes (2002, p. 70), evidencia que

As escolas públicas [de ensino médio] foram desorganizadas, seus currículos transformaram-se num amontoado de disciplinas, onde se misturavam as concepções positivistas do CFE [Conselho Federal de Educação] com os penduricalhos dos interesses do momento, como a educação moral e cívica.

Horizontes, v. 34, n. 1, p. 123-136, jan./jul. 2016 
No interior desse processo, os recursos humanos e materiais necessários para que toda a rede de ensino médio fosse tornada profissionalizante, mais uma vez, não foram alocados de forma adequada, e o que se presenciava era uma grande improvisação, inclusive na arregimentação de docentes para a continuidade do próprio curso.

De forma concomitante, nesse período, passei a ter acesso a amplas áreas de conhecimentos que representavam novos conteúdos e novas formas de aprendizagens, diversificando visões, sendo apresentado a outras referências e ampliando o repertório de experiências humanas numa época marcada pela restrição no dizer e na forma de fazer. Essa inserção me era possibilitada pelo estabelecimento de novas relações, no caso meu amigo e seu irmão, a amiga e os dois colegas do grupo de estudos.

A emergência do conhecimento teórico realizado inicialmente por meio dos estudos em História e Biologia, mediado pela leitura dos materiais oferecidos a nós, acabaram me envolvendo numa progressiva satisfação quanto às diferentes possibilidades de interpretação de um mundo que se alargava. De certa forma, a positividade frente à escola se colocava a mim de uma forma renovada, trazendo um tipo de satisfação proporcionada pela ampliação das referências, mas que implicava superar um conjunto de dificuldades que foram vividas como desafios e que levou à formação de grupos, nos quais os estudos e as realizações das tarefas promoveram outros desdobramentos.

A interação ocorrida com os dois amigos da encenação da peça propiciara a emergência de outros modos de ver, outro universo de valores, outros critérios de análise, os quais foram se dando a ver no convívio diário, quando se comentavam notícias e trocavam-se informações, assim como nos estudos e realização de atividades.

A forma como nos apropriávamos de algumas das atividades propostas ligava-se indissoluvelmente às respectivas formações socioaxiológicas de meus amigos originadas de processos localizados em ambiente escolar e outros espaços. De modo paulatino, fui me inserindo nesse novo contexto, vivido também como um processo tenso, uma vez que, do lugar de onde eu viera, eram outras as vozes de meu convívio. Essa tensão por vezes se apresentava como momentos de solidão, enquanto em outros como momentos de muita escuta, numa tentativa de apreensão desse conjunto de palavras inicialmente alheias a mim.
Nesse processo de interação, a realidade foi se tornando cada vez mais ampla, um concerto polifônico formado por vozes localizadas em diferentes áreas da produção intelectual humana (BAKHTIN, 2002).

Falavam, pela voz dos integrantes da família de meu amigo e de minha nova amiga, poetas, artistas, políticos, historiadores, filósofos, antropólogos, pensadores, etc. de tempos distantes; como também aqueles com os quais eles conviveram, seja no campo profissional, no da atuação políticopartidária, no lazer. Neste trabalho continuado de leitura e interpretação do mundo, seus dizeres colocavam em diálogo esses diferentes sujeitos, localizados nos variados tipos de atividades intelectuais, no momento em que eles estabeleciam uma interlocução comigo. Isso implicava certos acentos, na medida em que toda relação com a realidade também é atravessada por valores e, portanto, minha relação com a realidade não se dava de forma direta, mas mediada pelo social e pela semiótica.

Bakhtin (2002, p. 142) analisa as formas pelas quais nos relacionamos com as palavras alheias e aponta duas possibilidades ou tipos de relação. Segundo ele,

\section{[...] no processo de formação ideológica do homem [a assimilação da palavra de outrem] procura definir as próprias bases de nossa atitude ideológica em relação ao mundo e de nosso comportamento, ela surge aqui como a palavra autoritária e como palavra interiormente persuasiva (grifos do autor).}

Quando estabelecemos uma relação do primeiro tipo com as palavras de outrem, esta exige de nós adesão e reconhecimento. Nas palavras do autor citado, "ela se impõe a nós", "permanecendo nitidamente isolada e compacta" e não permite "interpretação e assimilação livre", mas admite apenas sua "transmissão".

Os objetos sociossemióticos que os membros daquela família me apresentaram eram provenientes de livros, revistas, recortes de artigos ou matérias de jornais, arquivos pessoais e que eram postos em locais de fácil acesso e integravam as conversas que se desenvolviam em torno dos temas contemporâneos que nos solicitavam expressão e nos lançavam em diferentes momentos da história pessoal, do país e do mundo. O relato dos episódios 
vividos, das tensões vivenciadas, das dificuldades experimentadas, dos desafios enfrentados ao longo da existência era entrelaçado com os episódios da história humana ocorridos em outros espaços e tempos.

A vida ganhava densidade e dramaticidade à proporção que se mostrava nos acontecimentos nos quais outras formas e conteúdos adquiriam expressão, articulando-se e desdobrando-se com as leituras a partir de então realizadas. E, assim, era possível vivenciar uma forma de articulação entre o mundo que se lia e o mundo em que se vivia.

Pode-se dizer, com Kramer (2001), que as leituras que passei a realizar e compartilhar se colocavam para mim como uma experiência, porque com ela se evocavam comentários sobre o que se tinha lido ou sobre o que se tinha escutado ou assistido. Nestes comentários, os assuntos tratados tinham continuidade, as palavras do autor, do enunciador eram reafirmadas ou contraditadas ou ainda complementadas. Ou eram ainda acompanhadas de outras palavras retiradas de outras referências ou recontextualizadas ou redimensionadas. E se colocavam como experiência na medida em que me permitiam um autoconhecimento, uma percepção de meu processo, sistematizando-o de certa forma, ao mesmo tempo em que nele interferiam.

Meu processo de transformação ideológica, um processo de escolha e de assimilação das palavras de outrem (BAKHTIN, 2002), foi, por assim dizer, reorientado e passou a adquirir outros modos de expressão, seja no dizer, seja nas possibilidades que começaram a surgir na forma escrita de pequenos contos e poesias que eram socializadas no interior desse mesmo grupo.

Ouvindo as narrativas das histórias vividas por aquelas pessoas, compartilhando das leituras e dos escritos, participando dos comentários e apreciações que se davam no imbricado processo de interlocução, assim como me inserindo no acesso e no conhecimento de outras formas humanas de registro e de expressão (filmes, obras artísticas, artesanato, música,...), fui sendo levado para além da minha condição inicial e temporalidade, colocandome, paulatinamente, em diálogo com questões e autores, formas e conteúdos outros, que foram edificando meu percurso de formação, constituindome e impulsionando minha caminhada como leitor, como agente social, como interpretador do mundo e das relações sociais em que participava.

Minha convivência com os membros da família de meu amigo possibilitou um excedente de visão que me permitiu reconceber a própria ideia de família, nas formas outras de relações entre pais e filhos e entre homem e mulher. E a literatura também me possibilitava certa continuidade na escuta das narrativas vividas e nas informações trazidas nos episódios que eram relatados, nos sentidos que se produziam.

A ressonância interna das leituras que eram realizadas, como afirmou Lacerda (2003, p. 248), foi "[...] determinando a seleção das obras seguintes, estabelecida também pela construção contextual, fortalecida e ampliada a cada leitura".

\section{À guisa de uma conclusão}

Ao narrar esses meus encontros com textos, os contextos em que eles se deram e os outros que, com suas práticas culturais, mediaram esses encontros, visualiza-se o conjunto de aprendizados que fui realizando e que me constituíram como leitor e produtor de textos. O exame das condições de produção de tais aprendizados, aqui referidos no encontro de e com meu percurso formativo, acabou evidenciando que sua gênese se localiza nas relações sociais vividas.

Nesse sentido, o tipo de leitor e professor que acabei me tornando possibilitou-me as condições (sociais) de acesso a certas práticas culturais e, portanto, à materialidade com que tem se dado o encontro com os textos, quais são eles e como têm se configurado os possíveis desdobramentos desse processo.

Quando se pensa a formação de um leitor mais como um resultado que como um processo, tende-se a enfatizar um produto genérico que parece realizar-se à maneira de uma propriedade adquirida de forma isolada e ahistórica. Isso traz algumas consequências em termos éticos e epistemológicos que podem ser percebidas no jogo de luz e sombras, conforme a ponderação de Gonçalves Filho (2004, p. 18):

A distribuição da luz e das sombras sobre os objetos, ambientes e corpos não é coisa que deveríamos tomar meramente como coisa física, o corriqueiro espetáculo de como o Sol ou a lâmpada faz figurar certos lados, deixando outros na penumbra, arquitetando o que vai brilhar e o que ficará no escuro. A iluminação é coisa também social. $O$ que vemos e o que deixamos e ver, o regime de

Horizontes, v. 34, n. 1, p. 123-136, jan./jul. 2016 
nossa atenção, é decidido segundo o modo como fomos colocados e como eventualmente nos recolocamos em companhia.

Numa perspectiva próxima, quando Benjamin (1987, p. 89) considera e, ao mesmo tempo, alerta para a impossibilidade de que o homem seja conhecido inteiramente como algo facilmente esgotável e lembra "o fato de que [o homem] é modificável por seu ambiente e de que ele pode modificar esse ambiente, isto é, agir sobre ele gerando consequências", ele também nega que isso se constitua em impedimento ao seu conhecimento. Ele convida seus leitores a refletir sobre os mecanismos de explicação que procuram "congelar" o que é dinâmico, "encerrar" o que é aberto e "finalizar" o que é inconcluso.

A perspectiva histórico-cultural, assumida aqui e também nos estudos que venho desenvolvendo como professor e como pesquisador, tem me possibilitado conhecer, pela narrativa das histórias de leitura, diferentes percursos, variadas possibilidades no caminho de formação de um leitor e encontrar uma multiplicidade de tipos de leitores no percurso de formação de professores, distante, portanto, de certas homogeneidades insistentemente reiteradas.

\section{Notas}

1 Dentre outros, cabe destacar os seguintes: Cândido Portinari (exposição de pinturas e biografia), Nelson Werneck Sodré (História da Imprensa no Brasil, Formação Histórica do Brasil, História da Burguesia Brasileira, Introdução à Revolução Brasileira), Caio Prado Jr. (Formação Econômica do Brasil), Chico Buarque de Hollanda (músicas e letras), Marx (Manifesto do Partido Comunista), Gilberto Gil (letras e músicas), Lênin (Esquerdismo: doença infantil do comunismo), Picasso (exposição de pinturas e resenhas históricas de sua vida e obra), Lasar Segal (exposição de pinturas e resenhas históricas de sua vida e obra), Jorge Amado (romances: Capitães de Areia, Os Subterrâneos da Liberdade, Mar Morto), Machado de Assis (leitura coletiva do conto: O medalhão, realizada pelo pai de meu amigo), Monteiro Lobato ( romance: O Jeca Tatu, relato oral feito pelo pai de meu amigo, O poço do Visconde, A Reforma da Natureza), Engels (Manifesto do Partido
Comunista, Dialética da Natureza, A Origem da Família, do Estado e a Propriedade Privada), Caetano Veloso (músicas e letras), Geraldo Vandré (músicas e letras), Mário de Andrade (Macunaíma), Oswald de Andrade (Antologia Poética com leitura coletiva feita pelo irmão do meu amigo de vários poemas, peça de teatro: O Rei da Vela, romance: Os Condenados), Cecília Meireles (antologia poética), Fernando Pessoa (antologia poética), Bertold Brecht (antologia poética), Gilberto Freire (Casa Grande e Senzala), Moniz Bandeira (Cartéis de Desnacionalização), Euclides da Cunha (romance: Os Sertões), Luis Carlos Prestes (relatos orais feito pelo pai de meu amigo), Gabriel Garcia Marques (romances: Cem Anos de Solidão, O Outono do Patriarca, Ninguém Escreve ao Coronel, Crônica de uma Morte Anunciada, O Enterro do Diabo), Alina Paim ( A Hora Próxima), Konstantin Fédin (Primeiras Alegrais), Tolstoi (contos), Dostoievski (contos), Antonio Calado (romances: Quarup, Bar Don Juan), Pablo Neruda (antologia poética), João Cabral de Melo Neto (antologia poética e Morte e Vida Severina), Guimarães Rosa (Romance: Grande Sertão: Veredas e o conto: A hora e a vez de Augusto Matraga), Stanislaw Ponte Preta (livro: O Festival de Besteiras que Assola o País), Frederico Garcia Lorca (antologia poética), Henfil (cartuns, cartas e tirinhas e o relato de viagem: Henfil na China) , Máximo Gorki (romance: A Mãe), Charles Chaplin (filmes: curtas e longas metragens), Maiacovisk (antologia poética), Osório Alves de Castro (escritor e amigo pessoal da referida família, cujo pai de meu amigo realizou a revisão e a datilografia dos seus romances: Porto Calendário e Maria Feche a Porta Prau Boi na Te Pegar). Cabe citar ainda algumas obras tais como: Ferro e Independência, de Osny Duarte Pereira; Cangaceiros e Fanáticos, de Rui Facó; A República Velha, de Edgard Carone; Da Senzala à Colônia, de Emília Viotti da Costa; Brasil em Perspectiva, organizado por Carlos Guilherme Mota.

\section{Referências}

BAKHTIN, M. Questões de literatura e de estética: 
a teoria do romance. São Paulo: Annablume, 2002.

. Estética da criação verbal. São Paulo:

Martins Fontes, 2000.

O freudismo: Um esboço crítico. São Paulo:

Perspectiva, 2001.

BAKHTIN M. VOLOCHINOV, V. Marxismo $e$ Filosofia da Linguagem. São Paulo: Hucitec, 2002.

BATISTA, A. A. G. Os professores são não-leitores? In: MARINHO, M.; SILVA, C. S. R. (Orgs.). Leituras do professor. Campinas, SP: Mercado de Letras, ABL, 1998. p. 23-60.

BENJAMIN, W. Magia e técnica, arte e política: Ensaios sobre a literatura e a história da cultura. Obras Escolhidas. São Paulo: Brasiliense, 1987.

BRITTO, L. P. L. Leitor interditado. In: MARINHO, M.; SILVA, C. S.. R. (Orgs.). Leituras do professor. Campinas, SP: Mercado de Letras, ABL, 1998. p. 6178.

CUNHA, L. A. Educação e desenolvimento social no Brasil. Rio de Janeiro: Francisco Alves, 1977.

CUNHA, L. A.; GÓES, M. O golpe na educação. 11. ed. Rio de Janeiro: Jorge Zahar, 2002.

FONTANA, R. A. C. "Contar a vida": possibilidades e contribuições dos relatos de experiência e das histórias de vida para o estudo dos processos de formação de professores. In: SOUZA, E. C. (Org.). Autobiografias, histórias de vida e formação: pesquisa e ensino. Porto Alegre: Edipucrs, 2006. p. 225-237.

FURTADO, C. Formação econômica do Brasil. Rio de Janeiro: Cia Editora Nacional, 1970.

GATTI, B. et al. Características de professores (as) de $1^{\circ}$ grau no Brasil: perfil e expectativas. Educação e Realidade, Porto Alegre, n. 48, p. 248-260, ago.
1994.

GHIRALDELli Jr., P. História da Educação. São Paulo: Cortez, 1990. (Coleção Magistério 2.o grau. Série Formação do Professor).

GONÇALVES FILHO, J. M. Apresentação. In: COSTA, F. B. Homens invisíveis: Relatos de uma humilhação pública. São Paulo: Globo, 2004.

GUEDES-PINTO, A. L. Rememorando trajetórias da professora-alfabetizadora. Campinas, SP: Mercado de Letras, São Paulo: Fapesp, 2002.

HOLLANDA, H. B.; GONÇALVES, M.A. Cultura e participação nos anos 60. São Paulo: Brasiliense, 1982 ,

KRAMER, S. Linguagem e história: o papel da narrativa e da escrita na construção de sujeitos sociais. In: FRIGOTTO, G.; CIAVATTA, M. (Orgs). Teoria e educação no labirinto do capital. Petrópolis, RJ: Vozes, 2001. p. 157-179.

LACERDA, N. G. Os peixes de Schopenhauer: leitura e classe pensante. In: VIELLA, M. A. (Org.). Tempos e espaços de formação. Chapecó, SC: Argos, 2003. p. 219-253.

LAHIRE, B. Sociologia de la leitura. Barcelona: Gedisa, 2004.

ORLANDI, E. Discurso e leitura. São Paulo: Cortez, 1993.

Campinas, SP: Pontes, 1996.

SETTON, M. da G. Professor: variações sobre um gosto de classe. Educação e Sociedade, Campinas, SP, n. 47, p. 73-96, abr. 1994.

VIGOTSKI, L. S. O manuscrito de 1929. Educação e Sociedade, Campinas: Cedes, n. 71, p. 23-44, 2000.

\section{Sobre o autor}

Carlos Toscano: Professor do Programa de Pós-Graduação em Educação da Universidade Estadual de Londrina, UEL-PR. 
Este texto é dedicado aos que me possibilitaram aprendizados para toda a vida:

Meus pais: Pedro (in memoriam) e Zilda (in memoriam)

e aos amigos: Julian, Seu Jonas (in memoriam), Dona Joaquina e Joninhas.

Recebido em novembro de 2014.

Aprovado em abril de 2015. 